\title{
Highly Efficient High-Voltage MOSFET Converter with Bidirectional Power Flow Legs
}

\author{
Hyung-Min Ryu ${ }^{\dagger}$ \\ ${ }^{\dagger}$ Department of Electrical Engineering, Dong-Eui University, Busan, Korea
}

\begin{abstract}
In terms of power loss, a MOSFET has two advantages over an IGBT with an antiparallel diode: purely resistive without an offset voltage in conduction and no tail current at turn-off. However, the reverse recovery characteristic of the body diode is so poor that MOSFETs have not yet been available for high-voltage power converters with bidirectional power flow legs. This paper introduces how MOSFETs can be fully applied to high-voltage power converters with bidirectional power flow legs in order to achieve high efficiency. With a bidirectional DC-DC converter with one leg as the simplest example, the basic circuit topology and operating principle are described in detail. The high efficiency and stable operation of the proposed converter are validated through experiments with a $1.5 \mathrm{~kW}$ prototype.
\end{abstract}

Key words: Bidirectional, Body diode, Highly efficient, MOSFET, Reverse recovery

\section{INTRODUCTION}

Highly efficient power converters have been recently proposed for various applications with high rates of operation, such as in air conditioners, photovoltaic power generators, and wind power generators [1]-[8]. These converters require additional cost, such as the increase in the number or cost of switching devices. However, the reduced power loss can save not only the cooling cost but also considerable amount of the energy due to the long operating time.

Fig. 1 shows the circuit topology of a boost DC-DC converter, which has one leg consisting of one lower IGBT and one upper diode. In terms of power loss, a MOSFET has two advantages over an IGBT: purely resistive without an offset voltage in conduction and no tail current at turn-off. Power loss can thus be reduced by replacing the lower IGBT with a MOSFET. Since a MOSFET has no offset voltage in conduction, the conduction loss becomes much less as the load decreases.

Fig. 2 shows the circuit topology of a bidirectional DC-DC converter whose leg comprises two pairs of IGBT and antiparallel diode. Unlike the unidirectional DC-DC converter in Fig. 1, the substitution of a MOSFET for a pair of IGBT and antiparallel diode cannot reduce power loss. This is inevitable because the poor reverse recovery of the

Manuscript received Sep. 9, 2013; accepted Jan. 8, 2014 Recommended for publication by Associate Editor Honnyong Cha.

${ }^{\dagger}$ Corresponding Author: hmryu@deu.ac.kr

Tel: +82-51-890-1670, Dong-Eui University

Dept. of Electrical Engineering, Dong-Eui University, Korea

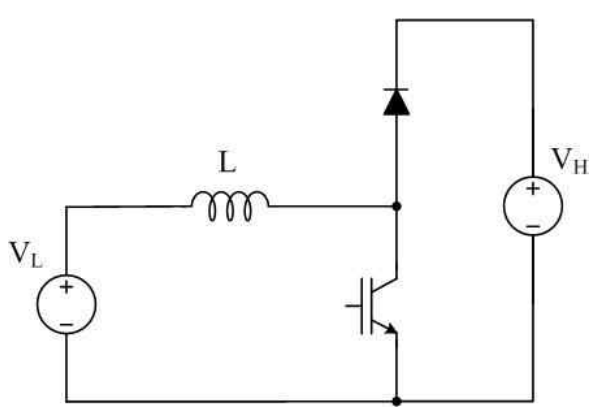

Fig. 1. Boost DC-DC converter.

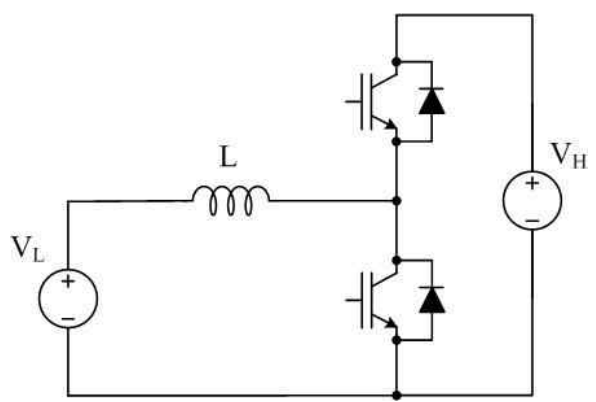

Fig. 2. Bidirectional DC-DC converter.

body diode causes a large amount of switching loss and because an inherent trade-off between $\mathrm{ON}$ resistance (conduction loss) and reverse recovery current (switching loss) exists. As a result, MOSFETs have not yet been available for high-voltage power converters with legs, in which power flow is bidirectional.

This paper introduces how MOSFETs can be applied to high-voltage power converters with bidirectional power flow 
legs in order to achieve high efficiency. The basic idea behind this study was obtained from [1], who introduced a highly efficient inverter system for air conditioner compressors. The three-phase PWM inverter adopts MOSFETs for three lower switches and uses discontinuous PWM where each lower MOSFET is fully turned ON for $120^{\circ}$ intervals in rotation. This setup maximizes the merit that a MOSFET has a lower conduction loss at a low current compared with an IGBT with an antiparallel diode. A large amount of the switching loss caused by the poor reverse recovery of the body diode is dramatically suppressed by adding a subsidiary switching circuit parallel to each MOSFET, which is a key idea. As a result, this solution shows remarkably high efficiency in actual operating conditions, where most of the time is spent under a light load.

In [1], MOSFETs are partially applied, or only used as the lower switch and only the basic concept is provided without a detailed description. The objective of this paper is to develop the basic concept so as to fully employ MOSFETs for high-voltage power converters with bidirectional power flow legs and also provide enough information for its implementation. With a bidirectional DC-DC converter with one leg as the simplest example, the basic circuit topology and operating principle are described in detail. The high efficiency and stable operation are validated through experiments with a $1.5 \mathrm{~kW}$ prototype. The proposed converter can be directly applied to, e.g. battery charger/dischargers for energy storage and can be simply extended to bidirectional interleaving DC-DC converters, single-phase converters, three-phase converters, and so on.

\section{PRoposed BidireCtional DC-DC CONVERTER}

Fig. 3 shows the circuit topology of the proposed bidirectional DC-DC converter. Compared with the conventional one in Fig. 2, two pairs of IGBT and antiparallel diode are both replaced by a MOSFET and also a subsidiary switching circuit is added parallel to each MOSFET in order to suppress the large switching loss caused by the poor reverse recovery of the body diode.

Fig. 4 shows the timing diagram of subsidiary switching and the current path corresponding to each time interval when the low-voltage source supplies the power. The features according to each time interval are as follows.

T1: The inductor current freewheels through the upper MOSFET S1. In order to reduce the conduction loss, S1 switches complementarily with the lower MOSFET S2.

$\mathrm{T} 2$ : S1 is turned off, and the inductor current flows only through S1's body diode. If S2 were turned on, the poor reverse recovery of the body diode would cause an undesirably large amount of switching loss, especially turn-on loss.

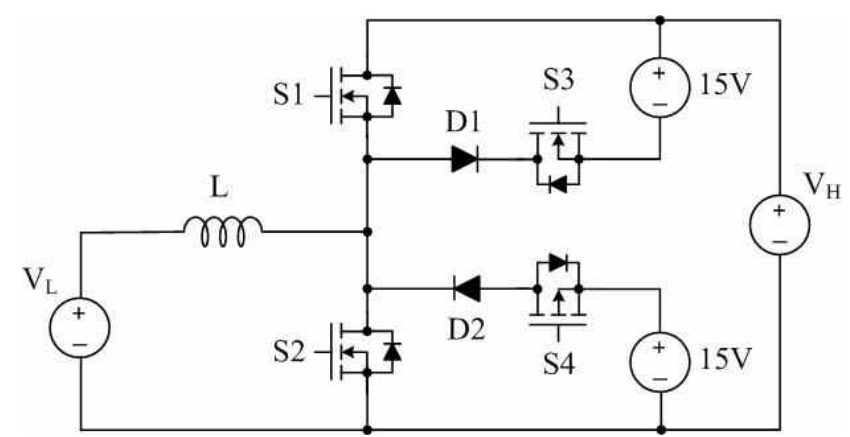

Fig. 3. Proposed bidirectional DC-DC converter.

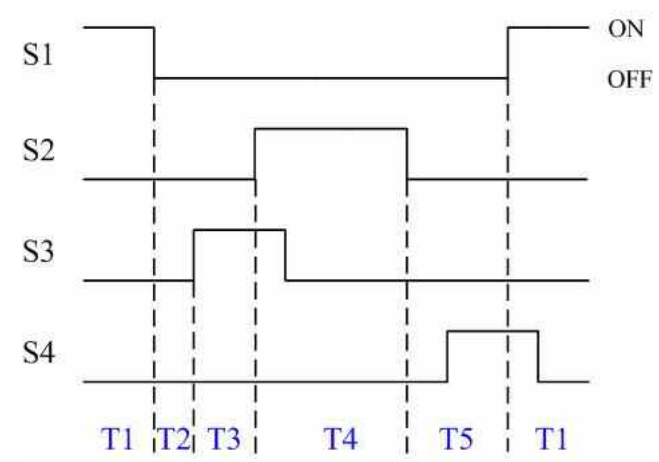

(a)

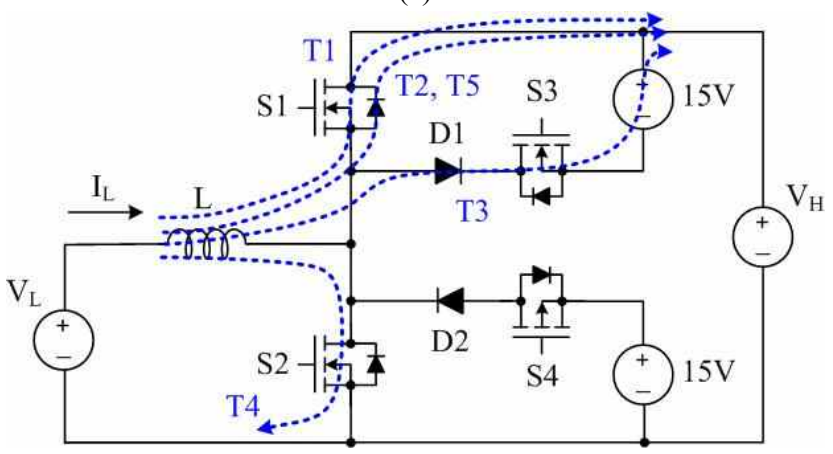

(b)

Fig. 4. (a) Timing diagram of subsidiary switching. (b) The current path corresponding to each time interval when the low-voltage source supplies the power.

T3: Prior to turning on S2, the MOSFET S3 of the upper subsidiary switching circuit should be turned on. The current freewheeling through S1's body diode is then transferred to S3. The poor reverse recovery of the body diode causes a large overshoot in S3's turn-on current. However, since S3's turn-on voltage falls from $15 \mathrm{~V}$, not a high voltage, the turn-on loss is negligible. The turn-off loss of the body diode is also negligible for the same reason.

T4: S2 is turned on. Since the overshoot of the turn-on current is decided by the reverse recovery current of fast recovery diode D1, the turn-on loss is similar to that of the conventional IGBT converter. S3 is then turned off; its turn-off loss is zero.

T5: S2 is turned off. The current is transferred to S1's body diode. Owing to diode D2, lower subsidiary switching has no effect. 


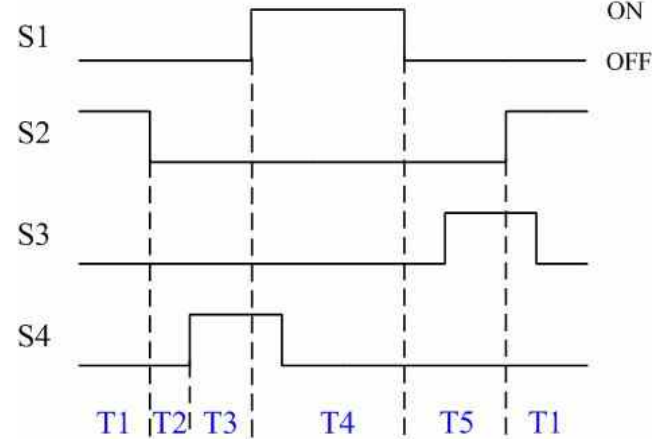

(a)

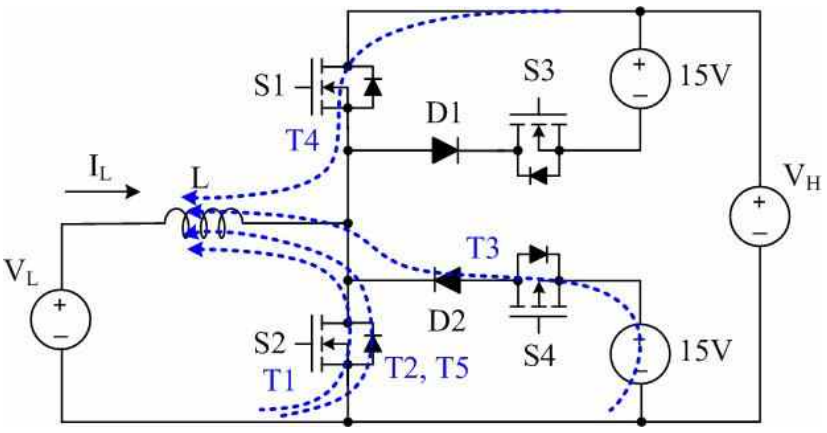

(b)

Fig. 5. (a) Timing diagram of subsidiary switching and (b) the current path corresponding to each time interval when the low-voltage source absorbs the power.

$\mathrm{S} 3$ is an N-channel MOSFET, and the voltage rating of 40 $\mathrm{V}$ is sufficient. Given that the conduction time is as short as 1 $\mu$ s to $2 \mu \mathrm{s}$, which is much shorter than the switching period, the current rating is also much lower than that of the main switches S1 and S2. The gate driver circuit can be implemented cost effectively with an HVIC, the high-side floating supply of which can be used in common with the $15 \mathrm{~V}$ voltage source of the subsidiary switching circuit. The voltage rating of fast recovery diode D1 should be as high as that of the main switches S1 and S2. However, the current rating is much lower for the same reason with subsidiary switch S3, or short duty. As a result, compared with the main switching circuit, the cost as well as the power loss of the subsidiary switching circuit is negligible.

Fig. 5 shows the timing diagram of subsidiary switching and the current path corresponding to each time interval when the low-voltage source absorbs the power. The circuit topology, operating principle, and part specifications can be all easily derived from the dual relationship with Fig. 4. For example, switch S4 of the lower subsidiary switching circuit is a P-channel MOSFET, and the gate driver circuit is implemented by a MOSFET driver IC with active low output.

The $15 \mathrm{~V}$ voltage source of the lower subsidiary switching circuit can be used in common with the supply of the gate driver for S2. On the other hand, the $15 \mathrm{~V}$ voltage source of the upper subsidiary switching circuit should be added separately. However, in the case of more than two legs, one $15 \mathrm{~V}$ voltage source can be used in common for the upper

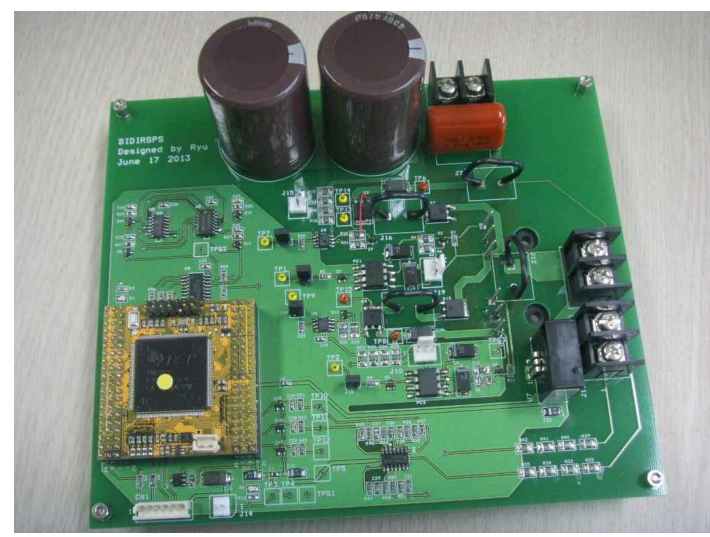

Fig. $6.1 .5 \mathrm{~kW}$ prototype.

TABLE I

SPECIFICATIONS OF A $1.5 \mathrm{KW}$ PROTOTYPE

\begin{tabular}{|l|l|}
\hline Rated power & $1.5 \mathrm{~kW}$ \\
Rated low voltage & $190 \mathrm{~V}$ \\
Rated high voltage & $380 \mathrm{~V}$ \\
Rated inductor current & $8 \mathrm{~A}$ \\
Inductance & $3 \mathrm{mH}$ \\
Switching frequency & $16 \mathrm{kHz}$ \\
\hline
\end{tabular}

TABLE II

Part Numbers of Switching Devices

\begin{tabular}{|l|l|l|}
\hline Solution & Switching device & Part number \\
\hline Conventional & IGBT(with FRD) & IKW10N60T \\
\hline \multirow{4}{*}{ Proposed } & Main MOSFET & IPW60R075CP \\
& Sub. N-ch. MOSFET & FDD8451 \\
& Sub. P-ch. MOSFET & FDD4243 \\
& Sub. FRD & IDD03E60 \\
\hline
\end{tabular}

subsidiary switching circuits unlike the supply of the gate driver for the upper main switch.

\section{EXPERIMENTAL RESULTS}

Table I shows the specifications of the $1.5 \mathrm{~kW}$ prototype (Fig. 6) used to validate the high efficiency and stable operation of the proposed bidirectional DC-DC converter. The part numbers of the switching devices are listed in Table II. The switching current and voltage were measured with a $100 \mathrm{MHz}$ (bandwidth) probe CP031 and a $100 \mathrm{MHz}$ differential probe ADP305, respectively. The measured waveforms were displayed and stored with a $400 \mathrm{MHz}$ digital oscilloscope WR44Xi-A, the product and integral functions of which were utilized to calculate the switching loss energy. The gate driver ICs for the N-channel MOSFET of the upper subsidiary switching circuit and the P-channel MOSFET of the lower subsidiary switching circuit are IR21171 and ICL7667, respectively. Time intervals $\mathrm{T} 2$ and $\mathrm{T} 3$ for the input voltage signals of the gate driver ICs are both $1 \mu$ s. 


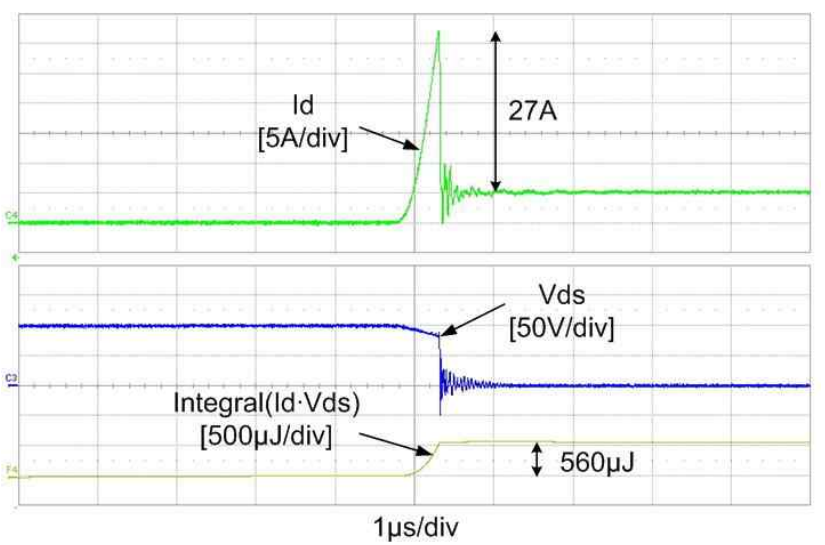

Fig. 7. Turn-on current, voltage, and energy loss of the upper MOSFET S1 without subsidiary switching when the low-voltage source absorbs the power.

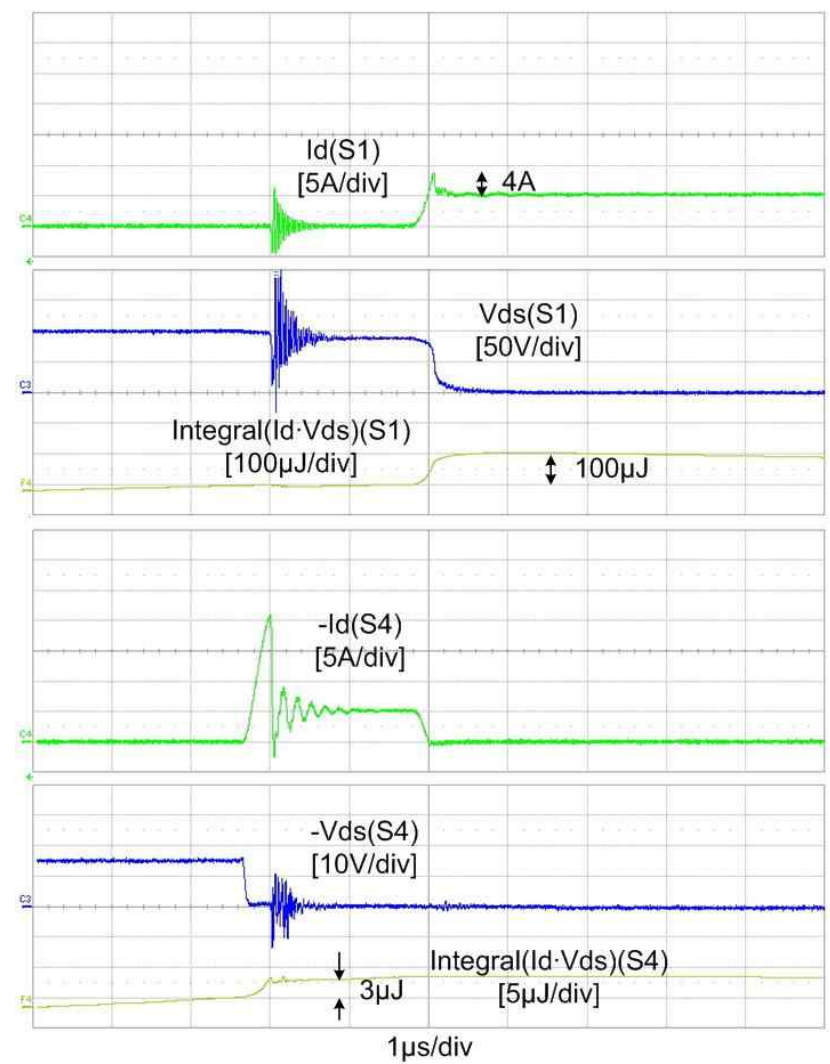

Fig. 8. Turn-on current, voltage, and energy loss of the upper MOSFET S1 and subsidiary switch S4 with subsidiary switching when the low-voltage source absorbs the power.

Fig. 7 shows the turn-on current, voltage, and energy loss of the upper MOSFET S1 without subsidiary switching when the low-voltage source absorbs the power. The test condition is $\mathrm{I}_{\mathrm{L}}=-5 \mathrm{~A}, \mathrm{di} / \mathrm{dt}=40 \mathrm{~A} / \mu \mathrm{s}, \mathrm{V}_{\mathrm{H}}=100 \mathrm{~V}$, and room temperature. The overshoot of the turn-on current is as large as $27 \mathrm{~A}$, which results in a large amount of turn-on loss, 560 $\mu \mathrm{J}$. The turn-off loss of the lower MOSFET S2's body diode is negligible because the softness factor is nearly zero. The large overshoot in the turn-on current with a high negative slope causes severe noise problems such as S2's overvoltage

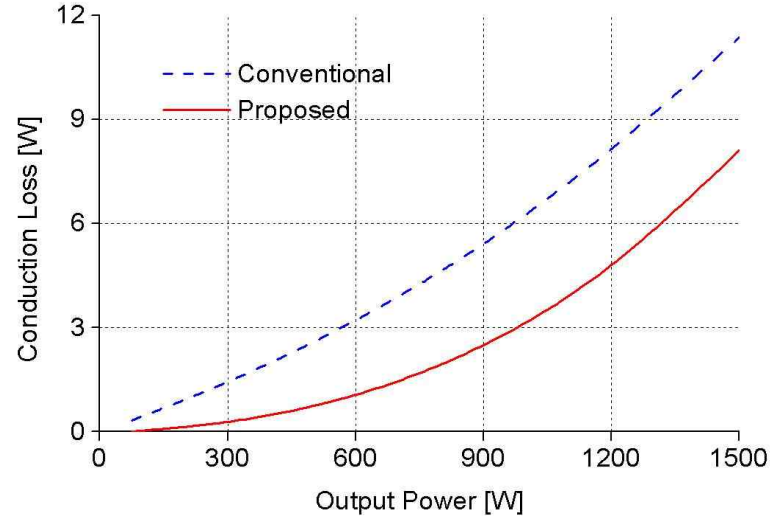

(a)

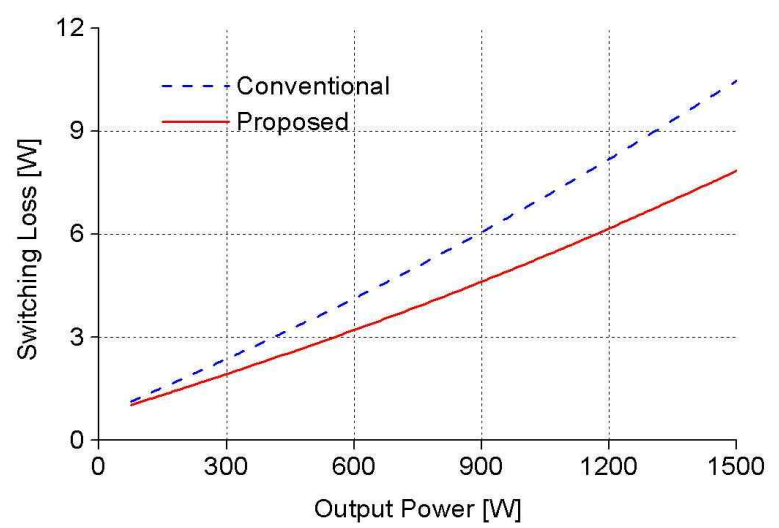

(b)

Fig. 9. Power loss comparison: (a) conduction loss, (b) switching loss.

stress, which is the reason the test condition is lower than the rating or the actual operating condition.

On the other hand, under the same test condition, the subsidiary switching dramatically reduces the current overshoot and turn-on loss to $4 \mathrm{~A}$ and $100 \mu \mathrm{J}$, respectively (Fig. 8). The turn-on loss of subsidiary switch S4 is only $3 \mu \mathrm{J}$. Unlike S1 without subsidiary switching, in order to mitigate noise problem, S4 can be slowly turned on with little effect on switching loss.

Fig. 9 provides a comparison of conduction and switching losses in the total switching devices according to the output power between the conventional method (Fig. 2) and the proposed method. The I-V curve of each switching device was referred from the datasheet provided by the manufacturer. Switching loss data were measured in the laboratory through a switching test. In order to take into account the temperature dependency all of the data were adequately interpolated between $25{ }^{\circ} \mathrm{C}$ and $125{ }^{\circ} \mathrm{C}$ depending on the output power. The power flow is from the low-voltage source to the high-voltage source. The opposite power flow results in almost the same power loss. Note that as the output power decreases the conduction loss of the proposed method becomes much less compared with the conventional method. 


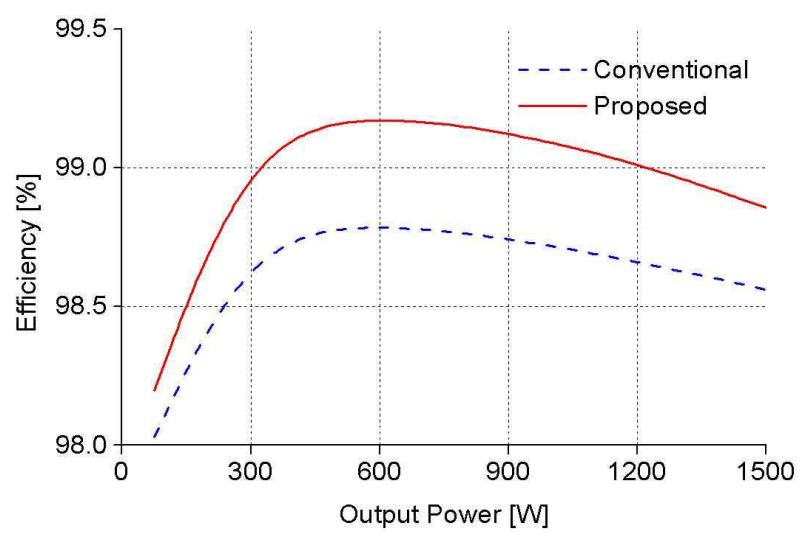

Fig. 10. Efficiency comparison.

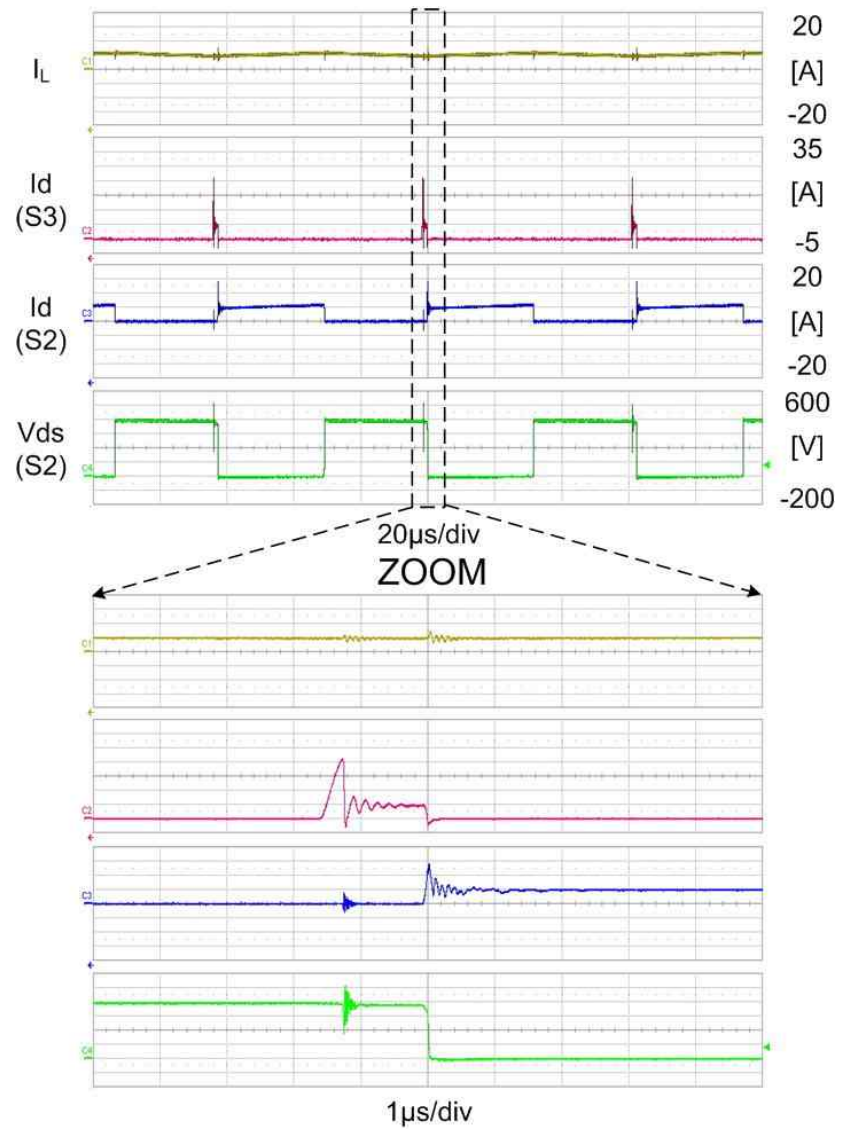

Fig. 11. Running test result when the low-voltage source supplies the power.

This result is due to the pure resistivity of a MOSFET. The reduction in switching loss is because a MOSFET turns off without a tail current. Compared with the conventional method, the power loss of the proposed method decreases to $59 \%$ and $72 \%$ at $50 \%$ and $100 \%$ of the rated load, respectively. From the power loss in Fig. 9, the efficiency according to the output power is given as Fig. 10. For a more reasonable comparison, especially at a light load, the power loss in the gate driving circuits is additionally considered.

Figs. 11 and 12 show the running test results when the low-voltage source supplies and absorbs the power,

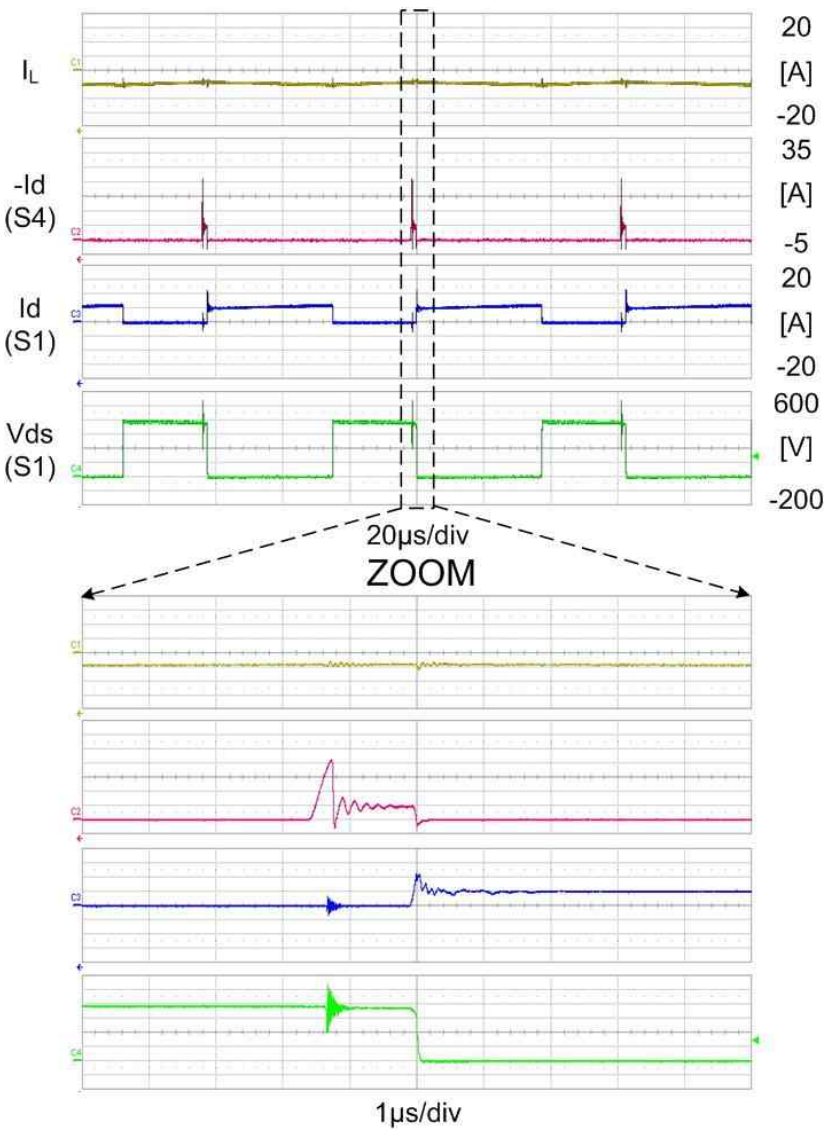

Fig. 12. Running test result when the low-voltage source absorbs the power.

respectively. Both the upper and lower subsidiary switching circuits work correctly, and the inductor current is stably controlled.

\section{CONCLUSIONS}

This paper presents how MOSFETs can be fully applied to high-voltage power converters with bidirectional power flow legs in order to achieve high efficiency. The key idea is to add a cost-effective subsidiary switching circuit parallel to a MOSFET, which dramatically suppresses a large amount of the switching loss caused by the poor reverse recovery of the body diode. The experimental results of a $1.5 \mathrm{~kW}$ prototype verify the high efficiency and stable operation of the proposed converter. Compared with highly efficient solutions that employ $\mathrm{SiC}$ MOSFETs or SiC JFETs, the proposed solution can achieve the same efficiency at lower cost.

\section{ACKNOWLEDGMENT}

This work was supported by Dong-Eui University, Busan, Republic of Korea (No. 2011AA162).

\section{REFERENCES}

[1] S. Shimizu, M. Uesugi, T. Toshi, T. Endo, and H. Mochikawa, "Application and development of high 
efficient inverter system for air conditioner," Domestic Conference of the Institute of Electrical Engineers of Japan, Industry Application, I-113, 2006 (Japanese).

[2] B. Burger and D. Kranzer, "Extreme high efficiency PV-power converters," 13th European Conference on Power Electronics and Applications, pp. 1-13, 2009.

[3] S. V. Araujo, P. Zacharias, and R. Mallwitz, "Highly efficient single-phase transformerless inverters for grid-connected photovoltaic systems," IEEE Trans. Ind. Electron., Vol. 57, No. 9, pp. 3118-3128, Sep. 2010.

[4] H. Schmidt, S. Christoph, and J. Ketterer, "Current inverter for direct/alternating currents, has direct and alternating connections with an intermediate power store, a bridge circuit, rectifier diodes and an inductive choke," German Patent DE10 221592 A1, Dec. 2003.

[5] M. Victor, F. Greizer, S. Bremicker, and U. Huebler, "Verfahren zum umwandeln einer elektrischen gleichspannung einer gleichspannungsquelle, insbesondere einer photovoltaik-gleichspannungsquelle in eine wechselspannung," German Patent DE102004 030912 B3, Jan. 2006.

[6] R. Gonzalez, J. Lopez, P. Sanchis, and L. Marroyo, "Transformerless inverter for single-phase photovoltaic systems," IEEE Trans. Power Electron., Vol. 22, No. 2, pp. 693-697, Mar. 2007.
[7] M. Frisch and T. Ernö, "Design concept for a transformerless solar inverter," Power Electronics Europe, Iss. 1, pp. 28-30, Jan./Feb. 2010

[8] H.-M. Ryu, "Highly efficient AC-DC converter for small wind power generators," Journal of Power Electronics, Vol. 11, No. 2, pp. 188-193, Mar. 2011

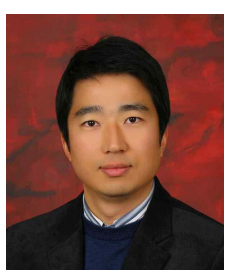

Hyung-Min Ryu was born in the Republic of Korea in 1975. He received his B.S., M.S., and Ph.D. degrees in electrical engineering from Seoul National University, Seoul, Republic of Korea, in 1997, 2000, and 2004, respectively. He worked as a research engineer at INTECH Factory Automation Company, Republic of Korea, from 2004 to 2006 . He also worked as an R\&D staff engineer (smart power module) at Fairchild Korea Semiconductor from 2006 to 2009. He has been a professor of electrical engineering at Dong-Eui University, Busan, Republic of Korea, since 2009. His research interests include the design and control of power conversion systems. 